\title{
Povos ciganos e Serviço Social: um necessário diálogo para o debate étnico-racial
}

\author{
Gypsies and Social Work: a necessary dialogue \\ for the ethnic-racial debate
}

\author{
Gabriela Alves dos Santos* \\ Priscila Fernanda Gonçalves Cardoso**
}

\begin{abstract}
Resumo - O presente artigo baseia-se em uma pesquisa documental e bibliográfica que tem como objetivo destacar a discussão sobre os povos ciganos como um importante diálogo no debate sobre raça e etnia no Serviço Social brasileiro. Para tanto, realiza um breve histórico sobre os povos ciganos e seu processo de marginalização no Brasil, demonstrando a vivência do preconceito, estigmatização e a criação de condições de vida precárias que os colocam como usuários das políticas sociais. Apresenta um levantamento e análise sobre o debate étnico-racial no interior do Serviço Social, a partir da formação profissional, produção intelectual e posicionamento das entidades da categoria, com destaque a (não) incorporação da discussão sobre os povos ciganos nesta questão. A partir disso, apresenta a necessidade do aprofundamento e ampliação do debate étnico-racial na profissão como instrumento de defesa dos direitos humanos em consonância com os princípios éticos profissionais.
\end{abstract}

Palavras-chave: povos ciganos; Serviço Social; racismo.

\begin{abstract}
This article is based on documentary and bibliographical research that aims to highlight a discussion about Gypsy peoples as an important dialogue in the debate about race and ethnicity in the Brazilian Social Work. To this end, a brief history about the Roma people and the process of marginalization they went through in Brazil is discussed, showing the experience of prejudice, stigmatization, and the creation of the precarious living conditions that enabled them as social services' users. Presenting research and analysis on the ethnic-racial debate within Social Work based on the professional training, intellectual production, and the stances of workers' organizations, this article highlights the (non) incorporation of the discussion about the Roma people in this debate. From this, the need for deepening and broadening the ethno-racial debate among social workers is presented as a defensive instrument of human rights in line with professional ethical principles.
\end{abstract}

Keywords: Gypsies; social service; racism.

\footnotetext{
* Bacharel em Serviço Social pela Universidade Federal de São Paulo (Unifesp).E-mail: gabs_alves@hotmail.com. ORCID: https://orcid.org/0000-0001-8558-8699.

** Assistente social, mestre e doutora em Serviço Social pela PUC/SP. Professora associada da graduação em Serviço Social e do Programa de Pós-Graduação em Serviço Social e Políticas Sociais da Unifesp. Membra do Grupo de Estudos e Pesquisa Fundamentos do Serviço Social: Ética, Formação e Trabalho da Unifesp. E-mail: pcardoso@unifesp.br. ORCID: https://orcid.org/0000-0002-3524-7623.
} 


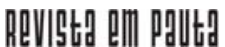

\} POVOS CIGANOS - SANTOS, G. A.; CARDOSO, P. F. G. \}

DOI: $10.12957 /$ REP.2020.51984

\section{Introdução}

O presente artigo busca fomentar a discussão sobre os povos ciganos no debate étnico-racial do Serviço Social brasileiro, considerando a importância desses grupos na formação histórica e cultural do Brasil. Porém, vale destacar que, quando falamos em povos ciganos, não nos referimos a uma única etnia, considerando que este é um grupo heterogêneo, subdivido em três grupos étnicos: Rom, Sinti e Calon, diferenciados pela sua cultura, língua e origem. Os Rom falam romanês e ainda subdividem-se em kalderach, machuaia, rudari, horahane e lovara, sendo um grupo originário da Europa Oriental, estando presentes no Brasil desde meados do século XIX; os Calon falam chib, são oriundos da Espanha e de Portugal, estando em território nacional desde o período colonial; por fim, os Sinti falam sinti, são provenientes predominantemente da Europa Central e emigraram para o Brasil, principalmente, após a Primeira e Segunda Guerra Mundial.

Isso posto, levamos em conta o fato de que esta população é também usuária dos serviços sociais, e que seu atendimento provoca inquietações e reflexões no campo dos valores e da ética. Objetivamos, porém, não cair em visões reducionistas que defendem um culturalismo que cria proposições relativistas no que concerne à ética e aos direitos humanos.

Entendemos que há que se apropriar do debate sobre a cultura e as formas de vida das diferentes etnias com as quais trabalhamos para podermos pensar estratégias de atuação que levem em conta tais questões. Assim, compreendemos que este deve ser um aprofundamento no campo da discussão étnico-racial, no qual a profissão vem se debruçando nos últimos anos.

Destarte, estruturamos o presente artigo da seguinte forma: apresentamos, na primeira parte, uma revisão bibliográfica sobre o processo de violação dos direitos dos povos ciganos no Brasil, desde o século XV até o século XX. Para tanto, tomaremos como referencial principal as produções de Moonen (2011) e Teixeira (2008), bem como faremos o resgate da legislação de imigração brasileira da década de 1940 como parte da pesquisa documental realizada. Na segunda parte do texto apresentamos um breve levantamento sobre a temática étnico-racial na profissão e a construção histórica deste debate, buscando compreender como a questão dos povos ciganos perpassa ou não esta temática na produção e formação em Serviço Social.

Tal levantamento se deu a partir da realização de pesquisa sobre a produção acadêmica nas plataformas da Unifesp, USP, Scielo, Google Acadêmico, WorldWideScience, Academia.edu, Dialnet e Bielefeld AcademicSearchEngine, a partir das palavras-chave: ciganos, Serviço Social, assistente social. Além disso, para os posicionamentos da categoria, utilizamos o portal do Conselho Federal de Serviço Social (CFESS) com as palavras-chave: ciganos, etnia, povos tradicionais, raça. Quanto ao levantamento 


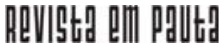

\} POVOS CIGANOS - SANTOS, G. A.; CARDOSO, P. F. G. \}

DOI: $10.12957 /$ REP.2020.51984

sobre a formação profissional, utilizamos como base o estudo realizado por Oliveira (2015) e, a partir das disciplinas por ela identificadas em 18 das 24 Instituições Federais de Ensino Superior (Ifes) com a temática raçaetnia, realizamos a leitura e análise das ementas de todas as que são consideradas obrigatórias.

Por fim, nas considerações finais, compreendendo os avanços que viemos conquistando no Serviço Social no Brasil no que se refere ao debate étnico-racial, tecemos algumas reflexões sobre a importância da inclusão e/ou explicitação da questão dos povos ciganos junto a este debate.

Tendo em vista que a categoria defende ${ }^{1}$ um exercício profissional isento de atos discriminatórios relacionados a questões de classe social, gênero, religião, nacionalidade, orientação sexual, identidade de gênero, idade, condição física e etnia, entende-se que a discussão sobre povos ciganos na profissão pode contribuir para refletir sobre estratégias de atendimento, bem como sobre demandas e especificidades culturais dessa população (mas não só), ancoradas no respeito à diversidade étnica e demais princípios e valores legitimados pela categoria profissional no projeto ético-político. Neste sentido, esperamos que este artigo possa servir como suscitador do início deste debate.

\section{Os povos ciganos e sua marginalização no Brasil}

Conforme apontado anteriormente, ao falarmos dos povos ciganos, temos diferentes etnias compondo este grupo. Neste sentido, faz-se necessário explicitarmos o que compreendemos por etnias, uma vez que estamos buscando defender a importância de o Serviço Social se apropriar do debate acerca dos diferentes grupos étnicos como parte da discussão ora realizada.

No século XIX, a partir da obra Ensaio sobre a desigualdade das raças humanas ${ }^{2}$, do filósofo Arthur de Gobineau (1816-1882), o termo raça era utilizado para designar diferentes grupos étnicos que, supostamente, tinham particularidades físicas, morais, psicológicas e intelectuais distintas. Nessa concepção, acreditava-se que existiam várias raças humanas, ocasionando uma hierarquização que, por conseguinte, legitimava o tratamento desigual dado a diversos grupos étnicos.

Naquele período, o desenvolvimento de produções científicas a respeito dessa temática contribuiu para a construção da teoria da supremacia racial branca, que nas de décadas de 1920 e 1930 foi apropriada, numa perspectiva imperialista, pelos Estados-Nações europeus, sustentando e legi-

\footnotetext{
1 Tais defesas fazem parte dos princípios e valores legitimados pela categoria profissional e são concretizados através de marcos regulatórios e resoluções, tais como o Código de Ética (1993), a Resolução CFESS n. 615/2011 e a Resolução CFESS n. 845/2018.

${ }^{2}$ Título em inglês The inequality of the human races (1915).
} 


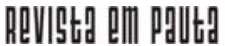

\} POVOS CIGANOS - SANTOS, G. A.; CARDOSO, P. F. G. \}

DOI: $10.12957 /$ REP.2020.51984

timando o genocídio de judeus, negros, homossexuais e ciganos durante a II Guerra Mundial.

Diferentemente da perspectiva biológica difundida no século XX, nesse artigo, ao se defender que a profissão incorpore raça/etnia no seu debate, entende-se que essa categoria analítica assume uma visão da realidade social. Considera-se, portanto, que ela ainda é um conceito difundido no tecido social que legitimou e legitima formas de dominação e exclusão, assumindo um caráter político e ideológico que se materializa, ainda hoje, nas formas de preconceito racial.

Apesar de, equivocadamente, raça e etnia serem compreendidas como sinônimo, elas se diferem; respectivamente, uma se refere a uma construção sociológica, enquanto que a outra faz menção a afinidades linguísticas e culturais de um grupo. Conforme, Munanga (2003, p. 12):

Uma etnia é um conjunto de indivíduos que, histórica ou mitologicamente, têm um ancestral comum; têm uma língua em comum, uma mesma religião ou cosmovisão; uma mesma cultura e moram geograficamente num mesmo território.

Destarte, compreendemos, neste artigo, os povos ciganos como etnias com características próprias, marcados historicamente por elementos socioterritoriais e culturais. Mesmo tendo a mesma etnia em diferentes países do mundo, alguns desses elementos têm sua particularidade na realidade brasileira, por exemplo.

Não se sabe ao certo a origem dos povos ciganos, pois é inexistente a escrita entre eles, dificultando a construção de uma história que faça jus ao local de onde eles se originaram. Somente no final do século XVIII os estudos linguísticos de Christian Büttner, em 1771 e, posteriormente os de Johann Rüdiger e Heinrich Grellmann, em 1782 e 1783, respectivamente, indicaram o parentesco entre as línguas ciganas e indiana, concluindo, então, que os ciganos haviam se originado na Índia.

O fato de eles serem ágrafos, ou seja, não utilizarem a representação escrita, dificulta tanto a construção dessa história inicial como a elaboração de uma produção autêntica. Assim, os registros existentes sobre esse povo, geralmente, se dão a partir do olhar do outro, que, majoritariamente, difundiu informações a partir de um ponto de vista estrangeiro e hostil ${ }^{3}$.

Embora haja tais estudos que indicam a origem dos povos ciganos, conforme Moonen (2011), a semelhança linguística não é suficiente para afirmar de onde eles vieram e, inclusive, muitos ciganos não sabem e não demonstram interesse em conhecer a origem de seus antepassados. Para o autor, o que existe é a consensualidade entre os estudiosos de que no século

${ }^{3} \mathrm{Na}$ antropologia, tal fenômeno é uma exemplificação do etnocentrismo, ou seja, quando o indivíduo passa a interpretar a cultura do outro a partir de suas normas e valores. Confira a explicação antropológica desse tema em Laraia (2011). 


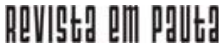

\} POVOS CIGANOS - SANTOS, G. A.; CARDOSO, P. F. G. \}

DOI: $10.12957 /$ REP.2020.51984

$\mathrm{X}$ ocorreu um forte movimento migratório dos ciganos. Essas ondas migratórias se assentaram no século $X V$, possivelmente em decorrência da peste negra e das guerras, quando eles chegaram ao solo ocidental. O primeiro registro de ciganos na Europa - datado de 1417 - revela o preconceito que eles vivem historicamente.

As primeiras notícias fidedignas datam de 1417, quando várias vezes há registro de ciganos na Alemanha. Já em Magdeburg informa-se que durante duas semanas estiveram na cidade 'os Tártaros, chamados ciganos', gente preta, horrível, tanto os homens quanto as mulheres, com muitas crianças, que foram expulsos de seu país e desde então vagavam pela terra. (MOONEN, 2011, p. 9).

Segundo o texto Povo cigano: o direito em suas mãos (BRASIL, 2007), os europeus acreditavam que os ciganos eram pessoas amaldiçoadas e/ou enviadas pelo demônio, por causa da cor mais escura de sua pele. Ao longo dos anos, leis foram feitas para proibir que os ciganos tivessem casamentos inter-raciais. Concomitantemente a isso, ainda existiam resquícios das lendas populares que rondavam a Europa na Idade Média, entre elas a de que os pregos da cruz de Jesus foram fabricados por um ferreiro cigano e, em decorrência desse fato, eles foram amaldiçoados com uma vida de vagância.

O preconceito racial e cultural, aliado às lendas populares, resultou em algumas tentativas de eliminação da cultura e da herança genética dos ciganos ${ }^{4}$. Além disso, o nomadismo tornou-se sinônimo de vagabundagem e as práticas de cartomancia e leitura das mãos passaram a ser associadas com feitiçaria/bruxaria, culminando para que o comportamento dos ciganos fosse rechaçado pela moralidade cristã. Neste contexto, a Igreja Católica e demais religiões cristãs passaram a persegui-los, sob a alegação de que eram hereges, já que não seguiam os sacramentos católicos, como por exemplo o batismo e o casamento.

Segundo Coelho (1995), o primeiro registro oficial de ciganos no Brasil é datado de 1574, quando a Coroa Portuguesa decretou que João Torres e sua família - filhos e esposa - fossem deportados para a colônia, devendo permanecer por cinco anos em terras brasileiras. Cabe mencionar que esse documento nos indica como se iniciou o processo de vinda dos ciganos para o Brasil, sendo possível afirmar que se tratava de uma política anticiganista de Portugal - presente também em demais países europeus -, que tinha como objetivo afastar esse grupo (tido como prejudicial aos bons costumes) das vistas da metrópole, além de expressar uma estratégia de povoamento das colônias.

No Brasil, os ciganos continuaram sendo perseguidos pelo Estado de forma sistemática. Por exemplo, em 1830 foi sancionado o Código

${ }_{4}^{4}$ Para conhecer mais sobre tais lendas e ações de eliminação da cultura cigana, ver Coelho (1995). 


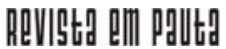

\} POVOS CIGANOS - SANTOS, G. A.; CARDOSO, P. F. G. \}

DOI: $10.12957 /$ REP.2020.51984

Criminal, o qual tinha como intuito assegurar a ordem no país através da aplicação de penas para crimes e delitos. Tal legislação fez com que a violência policial contra ciganos se aprofundasse, já que a vadiagem (art. 295) e a mendicância (art. 296) passaram a ser considerados crimes, cujas penas eram, respectivamente: prisão com trabalho de oito a 24 dias e prisão simples, ou com trabalho de oito dias a um mês. Neste contexto, os ciganos passaram a vivenciar um dos ápices da violência policial no Brasil, conhecida como o período da "correria dos ciganos"

Após a Abolição da Escravatura, políticos, cientistas e literatos passaram a discutir a imigração, juntamente com temas sobre urbanização e saúde pública, a fim de construir um projeto civilizatório no século XX que culminasse no progresso e na modernização do Brasil. Tais discussões contribuíram para que intervenções eugenistas fossem legitimadas e, neste contexto, o movimento eugênico não se restringiu a questões raciais, mas abarcava como degenerados todos aqueles que contribuíam para a "desordem" do Brasil, como por exemplo prostitutas, homossexuais e ciganos. Neste sentido, a preocupação das autoridades com a imigração também abarcava ciganos, já que estes imigravam expressivamente para o Brasil durante a Primeira e Segunda Guerra Mundial.

Na Era Vargas foi implementada uma política de imigração. Tratava-se de um Decreto - datado de 1938 - que dispunha sobre a entrada de estrangeiros no território nacional, no qual se fazia menção aos ciganos, conforme se observa abaixo:

Não será permitida a entrada de estrangeiros, de um ou outro sexo: II - Indigentes, vagabundos, ciganos e congêneres.

Art. $2^{\circ} \mathrm{O}$ Governo Federal reserva-se o direito de limitar ou suspender, por motivos econômicos ou sociais, a entrada de indivíduos de determinadas raças ou origens, ouvido o Conselho de Imigração e Colonização. (BRASIL, 1938, n. p.).

Como é possível perceber, o que se objetivava era a exclusão daqueles que, supostamente, comprometiam a "ordem e o progresso" do Brasil, sendo que os que aqui já viviam foram proibidos de usarem suas línguas maternas. A partir deste período não temos mais produções sobre a historiografia cigana no Brasil, o que nos deixa clara a necessidade do resgate desta história retomada junto ao próprio povo cigano.

Ao sistematizar essa trajetória, pudemos notar como o Estado brasileiro lidou com essas etnias e seu estilo de vida, desenvolvendo uma política anticiganista, que expressa o desprezo e a violência destinada a grupos que têm uma produção e reprodução da vida não pautada pela centralidade da propriedade privada.

${ }^{5}$ Esse período ficou conhecido como "correria dos ciganos" pois os relatórios dos chefes de polícia de Minas Gerais utilizavam, frequentemente, o subtítulo "invasão de ciganos" e "correrias de ciganos" para se referir à perseguição policial feita a este grupo. 


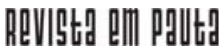

\} POVOS CIGANOS - SANTOS, G. A.; CARDOSO, P. F. G. \}

DOI: $10.12957 /$ REP.2020.51984

Para Murad (2015), o racismo destinado aos povos ciganos se iniciou antes mesmo do desenvolvimento científico do termo "raça" - cunhado no século XVIII com o lluminismo -, tendo em vista que, anterior a esse momento, já havia sido criado um estereótipo dos ciganos baseado em argumentos morais e éticos que resultavam em discriminação racial. Para a autora, essa discriminação se aprofundou com a emergência do capitalismo, pois ocorreu uma universalização da ética do trabalho (transformado em emprego), que condenava a preguiça comumente vinculada aos ciganos, uma vez que sua forma de produção e reprodução da vida se diferencia da venda da força de trabalho. Neste contexto, os ciganos passariam a ser retratados como avessos ao trabalho e aptos, naturalmente, ao canto e à dança, operando nessa perspectiva uma noção biológica e antissocial desses grupos étnicos.

Neste sentido, fica evidente como a criação de estereótipos dessas etnias pode conduzir tanto à marginalização dos povos ciganos como pessoas a serem temidas por serem "perigosas", "preguiçosas" e "invasivas", quanto a uma romantização como povos "adversários do sistema", o que também serve como justifica à marginalização. Nessa perspectiva, há o temor dos não ciganos de se tornarem como eles, sendo que esse medo se manifesta, muitas vezes, através do ódio e da discriminação racial que são destinadas a esses grupos étnicos.

Conhecer esta história nos traz elementos para entender a marginalização dos povos ciganos e sua relação com a pobreza no Brasil. Propicianos o desvelamento de suas condições de vida e a vivência das diferentes expressões da questão social enquanto grupo étnico no Brasil, colocandonos diante da possibilidade de um exercício profissional pautado por princípios éticos e não por juízos de valores baseados em preconceitos e estigmatizações difundidos sobre os povos ciganos. Dessa maneira, contribuise para que não se manifeste como racismo institucional no cotidiano profissional.

\section{Serviço Social, a temática étnico-racial e a (não) incorporação dos povos ciganos: um breve levantamento}

A expressão "questão social" é um termo utilizado a partir da terceira década do século XIX, a fim de designar a extrema pauperização do proletariado na Europa Ocidental e sua emergência no cenário político, durante o processo de industrialização iniciado na Inglaterra no final do século XVIII. Com o advento da Revolução Industrial, foi consolidado o modo de produção capitalista, que se baseia na simplificação das classes sociais em burgueses e proletariados, ou seja, entre aqueles que detêm os meios de produção e aqueles que, ao estarem desapropriados desses meios, precisam vender sua força de trabalho para garantir sua sobrevivência. Em síntese: 


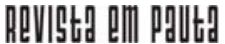

\} POVOS CIGANOS - SANTOS, G. A.; CARDOSO, P. F. G.

DOI: $10.12957 /$ REP.2020.51984

A questão social diz respeito ao conjunto das expressões das desigualdades sociais engendradas na sociedade capitalista madura, impensáveis sem a intermediação do Estado. Tem sua gênese no caráter coletivo da produção, contraposto à apropriação privada da própria atividade humana - o trabalho -, das condições necessárias à sua realização, assim como de seus frutos. É indissociável da emergência do 'trabalhador livre', que depende da venda de sua força de sua força de trabalho como meio de satisfação de suas necessidades vitais. A questão social expressa, portanto, disparidades econômicas políticas e culturais das classes sociais, mediatizadas por relações de gênero, características étnico-raciais e formações regionais, colocando em causa as relações entre amplos segmentos da sociedade civil e o poder estatal. (IAMAMOTO, 2001, p. 17 - grifos no original).

Assim, a análise da questão social implica a apreensão dos processos históricos e as formas de exploração/opressão que são estruturantes dessa sociabilidade, constituindo um sistema heteropatriarcal-racista-capitalista, com uma mesma estrutura mundial, mas com características próprias na formação dos diferentes continentes e países.

A apropriação deste debate pela categoria dos/as assistentes sociais recebe notoriedade a partir dos anos 1980 (com ênfase nos anos 1990), momento em que se torna evidente que o nosso objeto de trabalho são as manifestações da questão social, ou seja, o conjunto de expressões de desigualdades do modo de produção capitalista. A apreensão deste debate, neste momento, se deu centralmente vinculada à discussão do antagonismo das classes, com aporte da tradição marxista.

Ao mesmo tempo, é também nesta década que, a partir da vinculação dos/as assistentes sociais aos movimentos sociais em efervescência no processo de luta pela abertura democrática (contra a autocracia burguesa), o debate sobre raça/etnia ganha lugar no Serviço Social, não havendo, no entanto, uma vinculação direta com a discussão da questão social e da formação social, política e econômica do povo brasileiro. Segundo Silva (2006 apud JÚNIOR, 2003, p. 3-4):

O movimento negro estava em uma onda crescente de mobilização em torno da discussão racial e do lugar historicamente reservado ao negro na sociedade brasileira, de tal modo que a quase totalidade de assistentes sociais que encamparam esta discussão também estavam de alguma forma relacionados com a militância no movimento negro, fazendo com que a categoria acabasse por não conseguir se furtar a este debate.

Para o autor, o primeiro momento de reivindicação de raça/etnia como categoria analítica aconteceu no VI Congresso Brasileiro de Assistentes Sociais (CBAS), em 1989, com duas teses, intituladas A questão racial enquanto elemento de uma prática transformadora, de Maria José Pereira, Matilde Ribeiro e Selma Inês Alves de Deus, e O Serviço Social e os bas- 


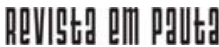

\} POVOS CIGANOS - SANTOS, G. A.; CARDOSO, P. F. G. \}

DOI: $10.12957 /$ REP.2020.51984

tidores do racismo, de Magali da Silva Almeida e Fátima Cristina Rangel Santana. Diante dessa reivindicação, no relatório final do congresso, houve a indicação para a inclusão de um eixo temático que discutisse raça/etnia e que viesse a garantir maior visibilidade para a questão (JúNIOR, 2003, p. 5).

No período de tal efervescência do debate étnico-racial no Brasil, os ciganos estavam aquém dos espaços deliberativos ${ }^{6}$ dessa temática. Somente nos anos 2000 ocorreu a primeira participação de um representante cigano - Cláudio lovanovictk - na Conferência de Direitos Humanos, tendo encaminhado a inclusão de todas as etnias ciganas no II Programa Nacional de Direitos Humanos (2002).

A inclusão dos povos ciganos neste debate inicia-se com a necessidade de implementar políticas públicas específicas para essas etnias, ganhando destaque a partir de 2003, quando houve a criação da Secretaria Especial de Promoção da Igualdade Racial (Seppir), ligada ao Governo Federal, em 21 de março. Essa secretaria tinha como competência a formulação, coordenação e articulação de políticas e diretrizes para a promoção da igualdade racial, com ênfase na população negra, embora também abarcasse indígenas, ciganos, árabes, palestinos, entre outros.

Em 2013, a Seppir se articulou com a Secretaria de Políticas para as Comunidades Tradicionais (Secomt), publicando o Guia de políticas públicas para povos ciganos, que orienta os ciganos a entrarem nas políticas sociais já existentes (BRASIL, 2013). Vale ressaltar que, conforme BRASIL (2017), em 2011, 215 Cras atendiam povos ciganos; esse número foi elevado para 450 no ano de 2016, expressando a aproximação dos ciganos aos serviços públicos, possivelmente pelo processo de reconhecimento das suas demandas e particularidades culturais pelo Estado.

Esse panorama e a compreensão do processo histórico de imigração dos povos ciganos para o Brasil (apresentados no item anterior) demonstram a importância de compreendermos as especificidades dos povos ciganos no universo do debate étnico-racial no Serviço Social. Neste sentido, realizamos um breve levantamento sobre como os povos ciganos aparecem (ou não) neste debate, a partir de aspectos vinculados à formação profissional, produção intelectual e posicionamento das entidades da categoria, utilizando os critérios já descritos na introdução.

Quanto à formação profissional, vale destacar que 18 das 24 Ifes do Brasil têm alguma disciplina relacionada à questão étnico-racial ${ }^{7}$. No entanto, dessas 18 Ifes, apenas sete ofertam disciplinas obrigatórias sobre esse tema, quais sejam: "Diversidade de gênero, raça, etnia no contexto dos Direitos Humanos", da Universidade Federal da Bahia (UFBA); "Classes e movimentos sociais" e "Capitalismo e questão social", da Universidade

\footnotetext{
${ }^{6}$ Os povos ciganos enfrentam dificuldades de representatividades nos espaços deliberativos por serem grupos heterogêneos. Além disso, durante muitos anos sua organização esteve vinculada a questões grupais e familiares. ${ }^{7}$ Dados retirados da pesquisa de Oliveira (2015), conforme descrito na introdução.
} 


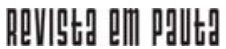

\} POVOS CIGANOS - SANTOS, G. A.; CARDOSO, P. F. G. \}

DOI: $10.12957 /$ REP.2020.51984

Federal do Rio Grande do Norte (UFRN); "Identidades culturais e Serviço Social no Brasil", da Universidade Federal do Rio de Janeiro (UFRJ); "Pensamento social brasileiro geral", da Universidade Federal dos Vales do Jequitinhonha e Mucuri (UFVJM); "Serviço Social: família e segmentos vulneráveis", da Universidade Federal de Santa Catarina (UFSC); "Cidadania e formação sócio-histórica do Brasil I", da Universidade Federal do Paraná (UFPR); e "Exclusão social e etnicidade", da Universidade Federal do Espírito Santo (Ufes).

Além disso, na maioria das Ifes (11), aparecem como disciplina eletiva: "Gênero, raça/etnia e política social", da Universidade Nacional de Brasília (UnB); "Saúde da população negra", da Universidade Federal de Alagoas (Ufal); "Relações étnico-raciais no Brasil e o Serviço Social", da Universidade Federal do Maranhão (UFMA); "Relações étnico-raciais no Brasil e o Serviço Social" e "Saúde, gênero e violência", da Universidade Federal de Pernambuco (UFPE); "Serviço Social nos estudos culturais" e "Antropologia afro-americana", da Universidade Federal do Recôncavo da Bahia (UFRB); "Políticas de ações afirmativas" e "Raça/etnia, gênero e sexualidades", da Universidade Federal de Ouro Preto (Ufop); "Gênero, raça e etnia", da Universidade Federal do Estado do Rio de Janeiro (UniRio); "Cultura afro-brasileira", da Universidade Federal de Uberlândia (UFU); "Educação e movimentos sociais", da Universidade Federal do Rio Grande do Sul (UFRGS); "Seminário diversidade étnico-cultural na Amazônia", da Universidade Federal do Pará (UFPA) e "Identidades e diferenças raça, gênero e classes", da Universidade Federal do Espírito Santo (Ufes).

Ao analisar o conteúdo das disciplinas obrigatórias, verificamos que as mesmas buscam as contribuições sociológicas da formação social do Brasil, com destaque ao processo de colonização e escravidão vivenciado por negros e indígenas, para refletir acerca da transversalidade da dimensão raça/etnia na questão social. A única menção feita aos ciganos foi nos objetivos da disciplina "Diversidade de gênero, raça, etnia no contexto dos direitos humanos", da Universidade Federal da Bahia (UFBA), quando é citada, de forma genérica, a necessidade de se identificar as iniciativas do Serviço Social para o combate de discriminação de diversos grupos, tais como mulheres, negros, indígenas, lésbicas, gays, bissexuais, travestis e queers (LGBTQ+), ciganos, entre outros.

No que tange à produção acadêmica, localizamos somente dois artigos que abordam a relação do Serviço Social com os povos ciganos, intitulados: A invisibilidade cigana no Brasil: que ações podem ser desenvolvidas pelo profissional de Serviço Social (MURTA; SANTOS; SILVA, 2016) e Povos ciganos, povo silenciado: desafios e possibilidade do Serviço Social (MARQUES, 2019).

\footnotetext{
${ }^{8}$ Sendo esta segunda produção publicada no processo de revisão deste artigo.
} 


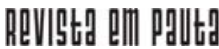

\} POVOS CIGANOS - SANTOS, G. A.; CARDOSO, P. F. G. \}

DOI: $10.12957 /$ REP.2020.51984

No que se refere ao posicionamento das entidades da categoria, realizamos levantamento no site do CFESS, identificando os encontros e publicações existentes sobre a temática étnico-racial nos últimos cinco anos (2015 a 2019). Assim, é possível afirmar o avanço e o amadurecimento em relação ao debate étnico-racial como um todo. Desde 2010, alguns seminários e ações têm sido organizados por este eixo, sendo que a partir do acúmulo de discussões, em dezembro de 2014, no colóquio ocorrido no XIV Encontro Nacional de Pesquisadores/as em Serviço Social (Enpess), em Natal, algumas propostas de ação foram deliberadas, abarcando o estímulo à pesquisa, formação profissional e articulação com os órgãos normativos e representativos da categoria.

Nota-se, ainda, que a discussão do racismo tem sido uma pauta com destaque desde a gestão "Tecendo na luta a manhã desejada", 20142017, quando foi publicado um caderno sobre racismo. Esse documento abordava de forma sintética e didática questões étnico-raciais, como por exemplo o que conceitualmente significa raça, etnia, racismo, racismo institucional e discriminação racial, trazendo também uma apresentação da importância das políticas de ação afirmativa para os negros como forma de enfrentamento ao racismo. Desde então, outras importantes campanhas têm sido realizadas, tais como "Assistentes sociais no combate ao racismo", em 2018, e a comemoração do dia do/a assistente social de 2019, "Se cortam direitos, quem é preta e pobre sente primeiro. A gente enfrenta o racismo no cotidiano!".

Em contrapartida, não encontramos nenhuma discussão específica sobre os povos ciganos nos documentos e posicionamentos das entidades da categoria presentes no debate étnico-racial. Diante deste levantamento, entendemos que, de modo geral, a questão étnico-racial ainda é uma temática recente dentro do Serviço Social brasileiro, e a categoria pode avançar nessa discussão incluindo diferentes etnias com as quais os/as assistentes sociais trabalham e/ou estudam, considerando que temos a possibilidade de problematizar como a questão racial está relacionada com as desigualdades sociais no Brasil.

Como pudemos notar, o conhecimento e o debate sobre os povos ciganos ainda é escasso no Serviço Social e nos convida a ampliar e aprofundar a discussão na categoria, pensando como as diferentes etnias podem ganhar espaço neste debate, dando sustentação ao trabalho profissional dos/as assistentes sociais na perspectiva de fortalecimento de um exercício profissional coadunado com os princípios éticos presentes em nosso código de ética. Dessa forma, lutamos pela "eliminação de todas as formas de preconceito, incentivando o respeito à diversidade, à participação de grupos socialmente discriminados e à discussão das diferenças", bem como na "defesa intransigente dos direitos humanos" (CFESS, 1993, n. p.). 


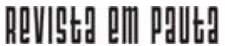

\} POVOS CIGANOS - SANTOS, G. A.; CARDOSO, P. F. G. \}

DOI: $10.12957 /$ REP.2020.51984

\section{Considerações finais}

O resgate da história dos povos ciganos no Brasil demonstrou que, ao longo dos séculos, o Estado brasileiro desenvolveu uma política anticiganista, representando o desprezo e a violência destinada a grupos que têm uma produção e reprodução da vida não pautadas pela propriedade privada.

Apesar de os ciganos apresentarem um estilo de vida diferente da sociedade dominante, estes não são uma sociedade independe e avessa ao trabalho. A condição de vida deles também está subsumida à lógica do capital e, no caso brasileiro, tem demonstrado um processo de marginalização e vivência em condições de pobreza e necessidades sociais. Entendemos que a discussão étnico-racial incorporada pelo Serviço Social nesses últimos 30 anos é fundamental para compreender processos vivenciados pela classe trabalhadora e pela formação desta classe na sociedade brasileira.

A apropriação da categoria analítica raça/étnica constitui-se, conjuntamente com a discussão de gênero, como uma ferramenta fundamental para apreensão crítica da questão social, considerando que os processos históricos de marginalização foram determinantes para a iniquidade econômica e social no Brasil. Essa convicção tem ganhado força na última década e o debate sobre a questão social tem se ampliado dentro da perspectiva marxista com a incorporação da discussão de gênero e raça/etnia como elementos constitutivos da questão social, sendo fundamentais para a compreensão da formação socioeconômica do Brasil.

O entendimento dessa sociedade exige compreender que as classes sociais não são meras abstrações, mas sim relações sociais que envolvem antagonismos inscritos em uma materialidade de corpos reais, que possuem sexo/sexualidade, raça/etnia. [...] Trata-se, ao contrário, de entender as particularidades da classe para compreendê-la na sua totalidade, sem perder a sua unidade em particularismos identitários, que ao dar ênfase apenas às diferenças, fragmentam, isolam e perdem o que temos em comum e que nos unifica: a necessidade de um projeto coletivo classista e emancipatório. (CISNE, 2018, p. 213).

Tal compreensão é resultado do amadurecimento teórico da categoria em relação a este debate, que está longe de ser homogêneo. A discussão de raça/etnia fortalece-se no interior dos debates, congressos e eventos do Serviço Social, demonstrando divergências e necessidades de aprofundamento, a fim de, inclusive, explicitar as concepções políticas e teóricas que envolvem esse assunto. Em nosso entender, reflete um processo de construção profícuo e necessário de afirmação desse debate como central para a compreensão da questão social. Diante de tal amadurecimento, acreditamos que se faz necessário, também, ampliar o escopo da discussão sobre raça/ etnia, trazendo elementos das diferentes etnias que estão presentes na 


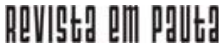

POVOS CIGANOS - SANTOS, G. A.; CARDOSO, P. F. G.

DOI: $10.12957 /$ REP.2020.51984

constituição da classe trabalhadora no Brasil com as quais os/as assistentes sociais trabalham. Para o/a profissional, torna-se um desafio compreender a discriminação étnico-racial a partir do cotidiano profissional, percebendo como ela se manifesta como violação de direitos.

Embora haja escassez de trabalhos acadêmicos e da discussão na formação profissional acerca dos povos ciganos, isso não significa que é inexistente o trabalho de assistentes sociais com essas etnias ou que esse não é um campo profissional. Neste sentido, vale ressaltar que atualmente os/as assistentes sociais atuam na formulação de políticas públicas específicas dos povos ciganos, bem como no atendimento direto às necessidades sociais dessa população. Está estabelecido na Política Nacional de Assistência Social (PNAS) que o atendimento para povos ciganos itinerantes, como populações nômades, se estabelecerá por meio de equipes volantes nos serviços socioassistenciais ou pela implantação do Centro de Referência de Assistência Social (Cras) Itinerante. Nas situações em que o município tem acampamento cigano fixo, o atendimento ocorre através de demanda espontânea e/ou busca ativa do Cras referência.

Sobre as condições de vida dos povos ciganos, empiricamente se observa que muitos ciganos, principalmente os Calons que vivem acampados, estão em bairros periféricos, exercendo o comércio ambulante e dedicando-se à prática de mendicância ${ }^{9}$. Não obstante, entre as principais demandas das famílias ciganas itinerantes, ou seja, aquelas que vivem em tendas, destaca-se como reivindicação central a implementação de obras de infraestrutura básica nos ranchos, como saneamento básico, coleta de lixo e eletrificação, a partir da inclusão das comunidades ciganas na Tarifa Social - Programa Luz para Todos (Lei n· 12.212/10, regulamentada pelo Decreto n. 7.583/11).

É importante destacar que atualmente, num processo lento, algumas pautas ${ }^{10}$ dos povos ciganos estão sendo reconhecidas pelo Estado, tanto que algumas reivindicações presentes na I Conferência Nacional de Promoção da Igualdade Racial (Conapir) já foram atendidas, tais como a realização dos mapeamentos oficiais feitos pelo Instituto Brasileiro de Geografia e Estatística (IBGE) sobre a quantidade de acampamentos ciganos no Brasil; a criação do "Cartão Educação", documento que viabiliza a matrícula de crianças e adolescentes ciganos - na condição de nômades - em redes públicas estaduais e municipais; e o acesso dos ciganos aos serviços de saúde sem comprovante de residência, já que este era inexistente pela sua condição de itinerância.

\footnotetext{
${ }^{9}$ A prática de mendicância é feita pelas mulheres ciganas e traz consigo elementos de uma sociabilidade patriarcal, na qual mulheres apanham dos seus maridos caso voltem sem dinheiro para casa. Problematizando essa questão, a partir do século XXI, em vários países tem surgido o feminismo cigano, com uma perspectiva interseccional em termos de gênero, raça e classe. Recomendamos a leitura de Rea (2017).

${ }^{10}$ Com o objetivo de pautar e assegurar os direitos sociais e culturais dos povos ciganos foi criado o Projeto de Lei do Senado n. 238/2015, que busca a criação do Estatuto do Cigano (BRASIL, 2015).
} 


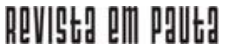

\} POVOS CIGANOS - SANTOS, G. A.; CARDOSO, P. F. G. \}

DOI: $10.12957 /$ REP.2020.51984

Considerando que as demandas citadas acima se vinculam às condições precárias de vida dos povos ciganos, bem como às particularidades culturais deles, entende-se que o/a assistente social, ao ser um/a profissional que atua na execução, formulação e gestão de políticas públicas, pode contribuir no desenvolvimento de ações de combate ao racismo e na elaboração e implementação de políticas públicas afirmativas para povos ciganos.

Neste sentido, defendemos que a formulação de estratégicas para o enfrentamento do racismo que acomete diversos grupos étnicos exige a necessidade de os currículos dos cursos de graduação do Serviço Social terem, obrigatoriamente, uma formação em que a questão étnico-racial seja vista como uma dimensão da questão social; que o debate dessa temática se amplie para os ciganos (e outros povos); e que a Academia valorize e incorpore os saberes profissionais que estão sendo produzidos, cotidianamente, no trabalho do/a assistente social com essa população.

Acreditamos que o debate acerca de raça/etnia no Serviço Social é fundamental para embasar o trabalho dos/as profissionais. Os dilemas éticos que se colocam no cotidiano de nosso trabalho são perpassados por nossas crenças, valores e formas de ver e estar no mundo. $\mathrm{O}$ contato com outras formas de estar no mundo não pode ser encarado com animosidade, preconceito ou rivalidade. É necessário conhecer e compreender nossas diferenças culturais, de costumes e formas de vida, reconhecendo nossa genericidade humana e as singularidades e particularidades étnico-raciais. Por fim, é mais do que fundamental seguirmos aprofundando este debate e qualificando nossa intervenção numa perspectiva emancipatória e de defesa dos direitos humanos. 


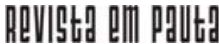

\} POVOS CIGANOS - SANTOS, G. A.; CARDOSO, P. F. G. \}

DOI: $10.12957 /$ REP.2020.51984

\section{Referências}

BRASIL. Decreto-Lei n. 406, de 4 de maio de 1938. Dispõe sobre a entrada de estrangeiros no território nacional. 1938. Disponível em: http://www. planalto.gov.br/ccivil_03/Decreto-Lei/1937-1946/Del0406.htm. Acesso em: 20 maio 2020.

BRASIL. Informativo atendimento a povos ciganos no SUAS. Brasília, 2017. Disponível em: http://www.mds.gov.br/webarquivos/publicacao/ assistencia_social/informe/Povos_Ciganos.pdf. Acesso em: 20 maio 2020.

BRASIL. Lei n. 12.212, de 20 de janeiro de 2010. Dispõe sobre a tarifa social de energia elétrica. Disponível em: http://www.planalto.gov.br/ ccivil_03/_ato2007-2010/2010/lei/l12212.htm. Acesso em: 20 maio 2020.

BRASIL. Lei de 16 de dezembro de 1830. Manda executar o Código Criminal. 1830. Disponível em: http://www.planalto.gov.br/ccivil_03/leis/lim/ lim-16-12-1830.htm. Acesso em: 20 maio 2020.

BRASIL. Povo cigano: o direito em suas mãos. Brasília, 2007. Disponível em: http://static.paraiba.pb.gov.br/2016/05/cartilha-ciganos.pdf. Acesso em: 20 maio 2020.

BRASIL. Guia de políticas públicas para povos ciganos. Brasília, 2013. Disponível em: https://bibliotecadigital.mdh.gov.br/jspui/handle/192/309. Acesso em: 20 maio 2020.

BRASIL. Lei do Senado n. 238/2015, que busca a criação do Estatuto do Cigano. Disponível em: https://www25.senado.leg.br/web/atividade/materias/ -/materia/120952. Acesso em: 20 maio 2020.

CFESS. Código de ética profissional do/a assistente social. Brasília: CFESS, 1993. CISNE, M. Feminismo e marxismo: apontamentos teórico-políticos para o enfrentamento das desigualdades sociais. Revista Serviço Social e Sociedade, São Paulo, n. 132, maio/ago. 2018.

COELHO, A. Os ciganos de Portugal. Lisboa: Dom Quixote, 1995.

GOBINEAU, J. A. The inequality of the human races. London: William Heinemann, 1915. Disponível em: https://archive.org/stream/inequalityofhu ma00gobi\#mode/2up. Acesso em: 20 maio 2020.

IAMAMOTO, M. V. A questão social no capitalismo. Revista Temporalis, Brasília, n. 3, 2001.

JÚNIOR, J. Questão racial e Serviço Social: um olhar sobre sua produção teórica antes e depois de Durban. Revista Libertas, Minas Gerais, v. 13, n. 1, jan./jul. 2013. Disponível em: https://libertas.ufjf.emnuvens.com.br/liber tas/article/view/2693. Acesso em: 20 maio 2020.

LARAIA, R. de B. Cultura: um conceito antropológico. São Paulo: Jorge Zahar, 2011. 


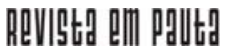

\} POVOS CIGANOS - SANTOS, G. A.; CARDOSO, P. F. G. \}

DOI: $10.12957 /$ REP.2020.51984

MARQUES, I. da S. Povos ciganos, povo silenciado: desafios e possibilidade do Serviço Social. In: ENCONTRO NACIONAL DE PESQUISADORES EM SERVIÇO SOCIAL, 16. 2019. Disponível em: https://periodicos.ufes.br/abe pss/article/view/23579. Acesso em: 20 maio 2020.

MOONEN, F. Anticiganismo: os ciganos na Europa e no Brasil. Recife, 2011. Disponível em: http://www.dhnet.org.br/direitos/sos/ciganos/a_pdf/ 1_fmanticiganismo2011.pdf. Acesso em: 20 maio 2020.

MUNANGA, K. Uma abordagem conceitual das noções de raça, racismo, identidade e etnia. In: III Seminário Nacional Relações Raciais e Educação, 2003. Rio de Janeiro: PENESB, 2003. Disponível em: https://www.geledes. org.br/wp-content/uploads/2014/04/Uma-abordagem-conceitual-dasnocoes-de-raca-racismo-dentidade-e-etnia.pdf. Acesso em: 20 maio 2020.

MURAD, L. C. Homo sacer e os ciganos: o anticiganismo - Reflexões sobre uma variante essencial e por isso esquecida do racismo moderno. Revista Pegada, São Paulo, 2015. Disponível em: http://revista.fct.unesp.br/ index.php/pegada/article/viewFile/3390/3025. Acesso em: 20 maio 2020.

MURTA, J. B.; SANTOS, A. P. C. dos; SILVA, A. M. de M. A invisibilidade cigana no Brasil: que ações podem ser desenvolvidas pelo profissional de serviço social? Revista Digital de Ciencias Sociales, Mendoza, v. 3, n. 5, 2016. Disponível em: http://revistas.uncu.edu.ar/ojs/index.php/millcadigital/article/view/768. Acesso em: 20 maio 2020.

OLIVEIRA, J. M. S. de. A transversalidade da questão étnico-racial nos currículos dos cursos de graduação em Serviço Social das universidades federais brasileiras. Dissertação (Mestrado em Estudos Interdisciplinares sobre a Universidade) - Universidade Federal da Bahia, Salvador, 2015. Disponível em: https://repositorio.ufba.br/ri/bitstream/ri/19825/1/DISSERTA\%C3 \%87\%C3\%83O\%20FINAL\%20JULIANA\%20MARTA\%20\%281\%29.pdf. Acesso em: 20 maio 2020.

REA, C. Redefinindo e definindo as fronteiras do pós-colonial. O feminismo cigano no século XXI. Estudos Feministas, v. 25, n. 1, 2017.

TEIXEIRA, R. C. História dos ciganos no Brasil. Recife: Núcleo de Estudos Ciganos, 2008. Disponível em: http://www.dhnet.org.br/direitos/sos/ciganos/ a_pdf/rct_historiaciganosbrasil2008.pdf. Acesso em: 20 maio 2020.

DOI: $10.12957 /$ rep.2020.51984

Recebido em 21 de julho de 2019.

Aprovado para publicação em 05 de fevereiro de 2020.

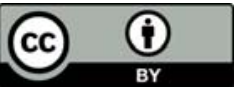

A Revista Em Pauta: Teoria Social e Realidade Contemporânea está licenciada com uma Licença Creative Commons Atribuição 4.0 Internacional. 